\title{
ENABLING BUSINESS AGILITY THROUGH INFORMATION TECHNOLOGY MANAGEMENT
}

\author{
V. Sambamurthy \\ Michigan State University \\ East Lansing, MI U.S.A. \\ Robert W. Zmud \\ University of Oklahoma \\ Norman, OK U.S.A. \\ Arun Rai \\ Georgia State University \\ Atlanta, GA U.S.A. \\ Robert Fichman \\ Boston College \\ Boston, MA U.S.A.
}

\section{OVERVIEW}

Agility is the organizational ability of a firm to continually sense promising competitive opportunities and respond through innovative moves in the form of new product introductions, new process improvements, new alliances, or other similar competitive actions. Given the intensifying nature of competition, globalization, and the high velocity of economic cycles, agility has become a prominent issue of interest to business and Information Systems professionals. Research attention to the connections between information technology management and business agility has begun to grow.

The goal of this panel is to offer alternative conceptualizations and perspectives on the enabling role of information technology management to develop agility as an organizational capability. The panelists develop conceptualizations that are anchored in different boundary disciplines for information technology management: strategic management, supply chain management, complex adaptive systems, and real options. Three questions are examined by each panel member. 
1. What is a significant challenge in promoting organizational attention to agility?

2. What conceptual frameworks will guide a better understanding about how to overcome these challenges in organizations?

3. What are the emerging implications for positioning information technology management as an enabler of agility?

\title{
2 POSITIONING IT MANAGEMENT AS A DIGITAL OPTIONS GENERATOR FOR AGILITY
}

\author{
V. Sambamurthy, Eli Broad Graduate School of Management, \\ Michigan State University
}

Existing conceptualizations of agility define it as the organizational ability to sense opportunities and threats in the business environment and respond through the appropriate assets and capabilities to seize those fleeting windows of competitive opportunities. Agility is regarded as an important organizational capability for contemporary firms. Studies have found that agile firms outperform other firms because of their ability to continually launch competitive moves. However, the role of agility in formulating corporate strategy is not fully resolved. Agility tends to be equated more with the exploration activities of firms. Therefore, an excessive focus on agility could lead to a lopsided investment in exploration capabilities to the detriment of exploitation and harvesting of current competitive position and capabilities. Therefore, there is a need to understand how firms balance attention to agility as another strategic behavior rather than an end in itself. This presentation will develop a portfolio perspective about strategic behaviors in corporate strategy that includes agility as one desirable behavior and capability.

Further, this presentation argues that information technology assets and capabilities provide firms with digital options to enable their portfolio of strategic behaviors. Based on ongoing field research, the presentation will outline the different ways in which information technology management could enable the portfolio of strategic behaviors and capabilities. The presentation will offer some implications for research and practice on the role of IT management in enabling business agility.

\section{THE ROLE OF AGILITY IN ENABLING MARKET POSITION: IMPLICATIONS FOR INVESTMENTS IN IT ASSETS AND CAPABILITIES}

Robert W. Zmud, Michael Price College of Business, University of Oklahoma

Crafting business strategies that produce, relative to competitors, above average returns has never been easy. Essentially, the aim is to position the firm within a product- 
market space such that the firm is able to provide a unique value proposition within the product-market space. If a firm is alone in a viable product-market space, the firm clearly holds a unique value proposition. Such a state, if it ever exists, does not last long as competitors will quickly enter product-market niches that are seen as generating above average returns. What is crucial, then, is both establishing a profitable strategic position and then being able to sustain the position over time.

Scholars studying how firms evolve their strategic positions have observed that two very different types of strategic actions are necessary: exploitative and exploratory. Exploitative strategic actions refer to systematic efforts directed to constantly improve the competencies associated with an existing strategic position. Exploratory strategic actions, on the other hand, refer to extemporaneous efforts directed at discovering new strategic positions or new competencies that might be instrumental in creating new strategic positions. Exploratory strategic actions create new product-markets. Once a new product-market is created, firms with favorable strategic positions in the productmarket strive to exploit their position in order to sustain the position. Other (known and unknown) competitors, however, engage in exploratory strategic actions in efforts to supplant this product-market through its radical transformation or through the creation of substitute product-markets. Inattention by an exploiting firm to the behaviors of the exploring firms carry the threat of locking a firm out of these emerging and attractive product-market spaces.

Strategic agility, of varying forms, as well as IT investments, of varying forms, are both required in enabling firms to undertake exploitative and exploratory strategic actions. Conceptual models are presented that suggest, given differing market environments and the nature of the strategic agility required within these market environments, appropriate levels of investment in both IT assets and IT capabilities. It is anticipated that these conceptual models will prove useful to executives desiring to appropriately align their levels of IT investment to specific strategic positions.

\section{A BUSINESS NETWORK PERSPECTIVE ON DIGITALLY-ENABLED AGILITY}

Arun Rai, Center for Process Innovation and Department of Computer Information Systems, Robinson College of Business, Georgia State University

The architecture of an interfirm business network has a profound impact on its agility and that of its member firms. It shapes the capability of business networks to dynamically balance emergent and predictable behavior. Complex adaptive systems, coupled with related theories on networks and allocation of decision rights, offer powerful theoretical perspectives to identify specific architectural considerations for business network agility. These considerations are (1) the relative distribution of hub and niche nodes and their networking ties, (2) the probabilistic distribution of the set of nodes and their intercomections, (3) the degree of aggregation and dimensionality of information and decision rules, and (4) the degree of homogeneity of interpretive and behavioral schema. The implications of these architectural considerations for digital-enablement of business network agility will be evaluated and illustrated using best practice exemplars. 


\title{
5 THE RELATIONSHIP BETWEEN REAL OPTIONS THINKING AND ORGANIZATIONAL AGILITY
}

\author{
Robert Fichman, College of Business, Boston College
}

Flexible information technology platform technologies are widely seen as key enablers of organizational agility. Yet, the uncertainty that attends IT platform investments renders traditional valuation approaches (e.g., based on NPV or ROI) wholly inadequate. Such approaches ignore the value of two forms of flexibility: (1) the value that flows from flexibility in how an investment project is managed, and (2) the value that results from flexibility in what the project produces, i.e., the degree of flexibility infused in the delivered platform itself. In response, a growing stream of research has advocated the application of options thinking to the valuation of uncertain IT investments. Early work focused on the application of real options pricing models to quantify investment value. However, these models are just the tip of the options thinking iceberg. No value will come from real options unless an organization has adopted a compatible management philosophy. In this presentation, Fichman I will present real options infusion as a construct to capture the extent to which a firm has assimilated a management philosophy based on options thinking. He will argue that real options infusion has three dimensions: the extent of options-oriented valuation tools; the extent of options-oriented project management processes; and extent of options-oriented organizational culture or norms. He will then explore the relationship between real options infusion and two types of agility. In particular, Fichman will argue that options infusion can be viewed as a complement to agile software development methods, and as an antecedent to business agility. 